MÜLLER : INOSITOL (INOSITE).

\title{
CLXVII.-Inositol (Inosite).
}

By Hugo Müller.

The difficulty which $\mathrm{I}$ experienced in securing a more abundant supply of cocosite (see preceding paper) for the continuation of its investigation led me to take up the study of the nearly related and isomeric inosite, of which I happened to possess a considerable quantity. This I had prepared years ago from the mother liquor of cochineal, in which I found it to be contained in appreciable quantity associated with tyrosine and guanine.

The behaviour of inosite would thus serve as a guide in the pursuit of the investigation of the cocosite, which would be all the more valuable as, on account of the great scarcity of this substance, the experiments with it have to be carried out with rather small quantities. In most cases, therefore, the experiments made with inosite preceded those made with cocosite. 
The main object of the present communication is to give the results which bave been obtained in the study of the reaction of a solution of hydrogen bromide in glacial acetic acid on inosite hexa-acetate.

As pointed out by Perkin and Simonsen ('Trans., 1905, 87, 855), this mode of bringing the hydrobromic acid into action affords a much more satisfactory and less destructive means than the employment of aqueous hydrobromic acid or the bromides of phosphorus.

I am indebted to Prof. W. H. Perkin, who had the compounds described in this paper analysed for me at the Schunck Laboratory, Manchester University, and also to Mr. T. V. Barker, who undertook their crystallographical investigation.

\section{Inosite Hexa-acetate.}

The inosite acetate used in this experiment was prepared by heating the anhydrous powdered inosite, in a flask provided with a long wide tube to act as a condenser, in quantities of 10 grams with 50 c.c. of acetic anhydride and 5 grams of fused zinc chloride. The reaction sets in with considerable energy, and continues without the further application of heat; but, in order to complete the operation, the contents of the flask were kept at the boiling point for about an hour, then allowed to cool, and the resulting scaly crystals repeatedly boiled with water. In this way, the theoretical quantity of hexa-acetate was invariably obtained.

The crystals were obtained from toluene.

System : monoclinic.

Ratios of the axes : $a: b: c=1 \cdot 1731: 1: 0.4395 ; \beta=101^{\circ} 58^{\prime}$.

Forms : $b=\{010\}, q=\{011\}, m=\{110\}, a=\{100\}$, and $o=\{\overline{2} 11\}$.

The habit is shown in Fig. 1. The form $o$ was observed on one crystal only.

Fis. 1.

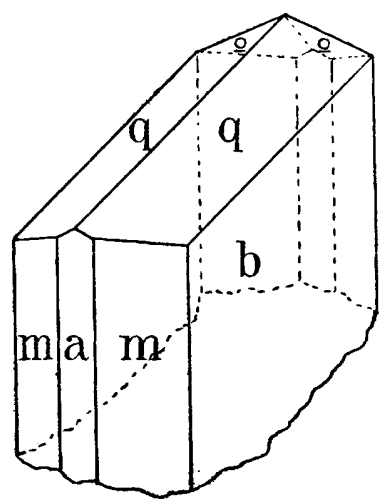

VOL. $\mathrm{XCI}$. 


\begin{tabular}{|c|c|c|c|c|}
\hline Angle. & $\begin{array}{l}\text { Nimber } \\
\text { of observa- } \\
\text { tions. }\end{array}$ & Iimits. & Mean. & Calculated. \\
\hline$\left\{\begin{array}{l}b: q=010: 011 \\
q: q^{\prime}=011: 011 \\
b: m=010: 110 \\
a: m=100: 110 \\
m: q=110: 011 \\
q: m^{\prime}=011: \overline{1} 10 \\
b: o=010: \overline{2} 11 \\
o: o^{\prime}=211: \overline{2} 11 \\
q: a=011: \overline{2} 11 \\
o: a^{\prime}=\overline{2} 11: \overline{1} 00\end{array}\right.$ & $\begin{array}{r}11 \\
5 \\
8 \\
6 \\
7 \\
7 \\
1 \\
1 \\
1 \\
2\end{array}$ & 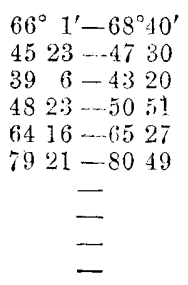 & $\begin{array}{ll}66^{\circ} & 44^{\prime} \\
46 & 23 \\
41 & 4 \\
48 & 59 \\
64 & 59 \\
79 & 58 \\
67 & 41 \\
\text { circa } & 41^{\circ} \\
,, & 36^{\circ} \\
,, & 62\end{array}$ & $\begin{array}{l}46^{\circ} 32^{\prime} \\
-\overline{5} \\
4858 \\
-50 \\
80 \quad 3 \\
6756 \\
42 \quad 4 \\
3752 \\
63 \quad 6\end{array}$ \\
\hline
\end{tabular}

Cleavage: none observable.

Optics: axial plane, normal to the symmetry place; axial angle, wide; the first negative mean line makes an angle of $64^{\circ}$ with the vertical axis in the acute angle $\beta$; birefringence, medium.

Specific gravity $=1 \cdot 271$. Mol. vol. $=340.04$.

Topic axes: $\chi=10 \cdot 286, \psi=8.7682, \omega=38539$.

This hexa-acetate, after recrystallisation from boiling alcohol, was now heated in quantities varying from 20 to 40 grams in sealed tubes with 50 c.c. or 100 c.c. respectively of glacial acetic acid saturated at $0^{\circ}$ with hydrogen bromide, for eight hours at $100^{\circ}$, then for another eight hours at $150^{\circ}$, and finally allowed to cool.

No pressure was noticed on opening the tubes, and on emptying the contents into water, a thick, white, semi-liquid mass separated which gradually became nearly solid. On heating this with water, it formed a heavy, almost colourless liquid which on cooling again solidified. This mass was now treated with cold alcohol, which dissolved part of it, and left a white, chalky, indistinct, crystalline substance.

It was soon recognised that this was a mixture of several compounds, the complete separation of which proved subsequently to be beset with great difficulty, and became, in fact, a most tedious and laborious process.

The part dissolved in the alcohol consisted mainly of a viscid substance, insoluble in water, whilst another portion of the product retained in the aqueous acetic acid liquor was obtained in the form of an almost colourless, but amorphous, substance very soluble in water.

This multiplicity of subitances formed in this reacticn, although interesting, was somewhat embarrassing, and some special trials were consequently made with the view of ascertaining whether perhaps the degrce of temperature, or time of reaction, had any influence in the 
formation of so many derivatives. These experiments, however, led to no tangible result and it became neces:ary subsequently to work up very considerable quantities of material in order to obtain the indiridual products in sufficient quantities for further examination.

In some of the operations, the contents of the tubes, after being mixed with water, were distilled in a vacuum in order to remove the acetic acid with the excess of hydrobromic acid, and it was then noticed that a small quantity of an oily liquid passed over with the first part of the distillate, which had the odour and other properties of bromobenzene.

For the further treatment of the white, chalky, crystalline product, recrystallisation from a suitable solvent was the only means of effecting the separation of its components, and after testing various solveuts, such as alcohol, acetone, benzene, toluene, and glacial acetic acid, absolute alcohol proved in the end the most advantageous medium. Boiling alcohol dissolves the substance, but, on cooling, nearly the whole of it separates as a crystalline magma consisting of various kinds of crystals. If, however, a very large quantity of alcohol, about 50 parts, is used, small, white, indistinct crystals separate first, which are followed by scaly crystals, and then more massive crystals make their appearance, but there are no very marked intervals, and at first only partial separation is attainable by watching the progress of the crystallisation and removing immediately each kind of crystal by filtration through a suitably warmed filter before the separation of another form sets in. By repeating this process many times, the separation is finally effected.

The small, white, and indistinct crystals, which sfparate first as the less soluble, are monobromoinosite penta-acetate, the scaly and the massive crystals are two isomeric forms of dibromoinosite tetra-acetate; in addition, a fourth, more soluble substance, crystallising in needles, is contained in the alcoholic mother-liquior, but it has not yet been obtained sufficiently pure for analyzis.

\section{Monobromoinosite Penta-acetate.}

This substance is deposited from its solution in the form of minute, indistinct, white crystals, whicb melt at $240^{\circ}$, and on cooling form a crystalline mass. It is insoluble in water; but soluble in benzene, toluene, chloroform, acetone, or glacial acetic acid, especially when warm. In cold alcohol it is very sparingly soluble, but more readily so on boiling. It was found that 0.5 gram required 75 c.c. of boiling absolute alcohol to dissolve it, whilst 100 c.c. of the saturated solution in the same medium at $20^{\circ}$ only contained 0.015 gram. With a methyl-alcoholic solution of sodium methoxide, it becomes a deep orange- 
brown, and is decomposed by it on boiling. The solution thus formed reduces Fehling's solution. When heated with alcoholic ammonia in a sealed tube at $100^{\circ}$, it gradually dissolves and is decomposed. The colourless product is readily soluble in water, but has not yet been separated from the ammonium acetate and obtained in a crystalline condition.

When acted on by zinc, dust a reduction product is obtained (p. 1791). On analysis :

0.1852 gave $0.2873 \mathrm{CO}_{2}$ and $0.770 \mathrm{H}_{2} \mathrm{O} . \quad \mathrm{C}=42 \cdot 3 ; \mathrm{H}=4 \cdot 6$.

$0.2843,0.1209 \mathrm{AgBr} . \quad \mathrm{Br}=18.0$. $\mathrm{C}_{6} \mathrm{H}_{6} \mathrm{Br}\left(\mathrm{O} \cdot \mathrm{CO} \cdot \mathrm{CH}_{3}\right)_{5}$ requires $\mathrm{C}=42 \cdot 4 ; \mathrm{H}=4 \cdot 6 ; \mathrm{Br}=17 \cdot 7$ per cent.

\section{Dibromoinosite Tetra-acetate.}

When quite pure, this substance can be obtained from its alcoholic solution in remarkably fine transparent crystals of more than a centimetre in diameter. It melts at $140^{\circ}$ to a clear liquid, which on cooling forms a glass-like nass without any sign of crystallisation; but when scratched begins to crystallise and large, distinct crystals are formed in the solid mass.

It is insoluble in water, but soluble in glacial acetic acid, benzene, toluene, chloroform, or acetone, especially when hot. 100 c.c. of absolute alcohol at $20^{\circ}$ dissolve 1.0 gram and 100 c.c. of boiling absolute alcohol dissolve $62 \cdot 0$ grams.

'The hot alcoholic solution is a powerful solvent for the other compounds formed along with it by the action of hydrogen bromide on inosite hexa-acetate. When boiled with alcoholic potash, the alcoholic solution turns a deep orange-brown colour and reduces Fehling's solution. Alcoholic ammonia decomposes it gradually, even in the cold, without causing any coloration, and the presence of bromine is then indicated by the addition of silver nitrate.

When acted on by zinc dust, it is decomposed into acetic acid and phenol (p. 1790). On analysis :

0.2237 gave $0.2861 \mathrm{CO}_{2}$ and $0.0726 \mathrm{H}_{2} \mathrm{O} . \quad \mathrm{C}=34.9 ; \mathrm{H}=3 \cdot 7$.

$0 \cdot 2207,0 \cdot 1740 \mathrm{AgBr} . \quad \mathrm{Br}=33 \cdot 6$.

$\mathrm{C}_{6} \mathrm{H}_{6} \mathrm{Br}_{2}\left(\mathrm{O} \cdot \mathrm{CO} \cdot \mathrm{CH}_{3}\right)_{4}$ requires $\mathrm{C}=35 \cdot 5 ; \mathrm{H}=3 \cdot 8 ; \mathrm{Br}=33 \cdot 7$ per cent.

System : anorthic.

Ratios of the axes: $a: b: c=1.0644: 1: 0.9153, \quad a=112^{\circ} 10^{\prime}$, $\beta=116^{\circ} 7^{\prime}, \gamma=74^{\circ} 3^{\prime}$.

Forms : $b=\{010\}, m=\{110\}, a=\{100\}, \quad n=\{1 \overline{1} 0\}, \quad o=\{011\}$, $c=\{001\}, q=\{011\}, p=\{111\}, d=\{101\}, k=\{111\}, x=\{\overline{5}, \overline{7}, 12\}$, and $e=\{\overline{7} 04\}$.

The habit of the crystals was slightly prismatic, the forms $m, a$, 
and $c$ predominating. Of the remaining forms, $d, k, q$, and $n$ were always of considerable size, whilst $o, p$, and $b$ were more subordinate; $p$ often failed, and $e$ and $x$ were observed but once (Fig. 2 is a pro-. jection normal to the prism zone).

FIG. 2.

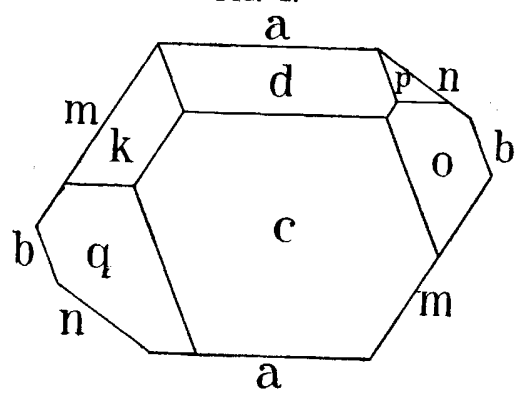

\begin{tabular}{|c|c|c|c|c|c|}
\hline Angle. & $\begin{array}{l}\text { No. of } \\
\text { observa- } \\
\text { tions. }\end{array}$ & Limits. & Mean. & Calc. & Diff. \\
\hline$\left\{\begin{array}{l}b: m=010: 110 \\
m: a=110: 100 \\
a: n=100: 1 \overline{1} 0 \\
n: b^{\prime}=1 \overline{1} 0: 0 \overline{10}\end{array}\right.$ & $\begin{array}{l}11 \\
20 \\
17 \\
12\end{array}$ & $\begin{array}{lrrr}47^{\circ} & 36^{\prime} & -48^{\circ} & 2^{\prime} \\
49 & 33 & -50 & 6 \\
41 & 44 & -42 & 17 \\
40 & 2 & -40 & 38\end{array}$ & $\begin{array}{l}47^{\circ} 49^{\prime} \\
4947 \\
42 \quad 2 \\
4023\end{array}$ & $\begin{array}{l}47^{\circ} 44^{\prime} \\
- \\
4027\end{array}$ & $\frac{5^{\prime}}{-}$ \\
\hline$\left\{\begin{array}{l}b: o=010: 011 \\
o: c=011: 001 \\
c: q=001: 0 \overline{1} 1 \\
q: b^{\prime}=0 \overline{1} 1: 0 \overline{1} 0 \\
b: c=010: 001\end{array}\right.$ & $\begin{array}{r}12 \\
18 \\
19 \\
15 \\
3\end{array}$ & $\begin{array}{rrrr}39 & 33 & -39 & 42 \\
33 & 0 & -33 & 24 \\
47 & 12 & -47 & 40 \\
59 & 39 & -59 & 59 \\
72 & 37 & -72 & 44\end{array}$ & $\begin{array}{rr}39 & 38 \\
33 & 9 \\
47 & 23 \\
59 & 49 \\
72 & 42\end{array}$ & $\begin{array}{lr}39 & 39 \\
33 & 4 \\
47 & 34 \\
59 & 42 \\
72 & 43\end{array}$ & $\begin{array}{r}1 \\
5 \\
11 \\
7 \\
1\end{array}$ \\
\hline$\left\{\begin{array}{l:l}b: p=010: \overline{1} 11 \\
p: d=\overline{1} 11: \overline{1} 01 \\
d: k=\overline{1} 01: \overline{1} 11 \\
k: b^{\prime}=\overline{111}: 0 \overline{0} 0 \\
b: d=010: \overline{1} 01\end{array}\right.$ & $\begin{array}{r}1 \\
3 \\
13 \\
9 \\
6\end{array}$ & $\begin{array}{llll} & & - & \\
29 & 48 & -29 & 54 \\
48 & 15 & -48 & 40 \\
64 & 39 & -64 & 46 \\
66 & 37 & -66 & 57\end{array}$ & $\begin{array}{ll}36 & 49 \\
29 & 51 \\
48 & 32 \\
64 & 44 \\
66 & 42\end{array}$ & $\begin{array}{ll}36 & 55 \\
29 & 54 \\
48 & 34 \\
64 & 37 \\
66 & 49\end{array}$ & $\begin{array}{l}6 \\
3 \\
2 \\
7 \\
7\end{array}$ \\
\hline$\left\{\begin{array}{l}m: o=110: 011 \\
o: d=011: \overline{1} 01 \\
d: m^{\prime}=\overline{1} 01: \overline{1} 10\end{array}\right.$ & $\begin{array}{r}12 \\
10 \\
9\end{array}$ & $\begin{array}{llll}43 & 25 & -43 & 44 \\
47 & 36 & -47 & 49 \\
88 & 40 & -88 & 59\end{array}$ & $\begin{array}{ll}43 & 31 \\
47 & 43 \\
88 & 45\end{array}$ & $\begin{array}{l}4328 \\
4752 \\
8840\end{array}$ & $\begin{array}{l}3 \\
9 \\
5\end{array}$ \\
\hline$\left\{\begin{array}{l}m: c=110: 001 \\
c: k=001: \overline{1} 11 \\
k: m^{\prime}=\overline{\mathbf{1} 11}: \overline{\mathbf{1} 10}\end{array}\right.$ & $\begin{array}{l}24 \\
15 \\
15\end{array}$ & $\begin{array}{lllll}59 & 11 & -59 & 30 \\
65 & 14 & -65 & 51 \\
54 & 53 & -55 & 25\end{array}$ & $\begin{array}{ll}59 & 17 \\
65 & 28 \\
55 & 14\end{array}$ & $\begin{array}{l}-\overline{6534} \\
559\end{array}$ & $\begin{array}{c}-6 \\
5\end{array}$ \\
\hline$m: q=101: 0 \overline{1} 1$ & 14 & $\begin{array}{llll}93 & 3 & -93 & 19\end{array}$ & 9311 & 9320 & 9 \\
\hline$m: p=110: \overline{1} 11$ & 4 & $6933-6938$ & 6936 & 6933 & 3 \\
\hline$\left\{\begin{array}{l:l}a & : o=100: 011 \\
o: p=011: \overline{1} 11 \\
p: a^{\prime}=\overline{1} 11: \overline{1} 00 \\
o: a^{\prime}=011: \overline{1} 00\end{array}\right.$ & $\begin{array}{l}7 \\
2 \\
2 \\
5\end{array}$ & $\begin{array}{rrrr}79 & 37 & -80 & 11 \\
31 & 5 & -31 & 8 \\
68 & 51 & -69 & 2 \\
99 & 56 & -100 & 20\end{array}$ & $\begin{array}{rr}79 & 55 \\
31 & 6 \\
68 & 57 \\
100 \quad 7\end{array}$ & $\begin{array}{rr}79 & 45 \\
31 & 9 \\
69 & 6 \\
100 & 15\end{array}$ & $\begin{array}{r}10 \\
3 \\
9 \\
8\end{array}$ \\
\hline
\end{tabular}




\begin{tabular}{|c|c|c|c|c|c|}
\hline Angle. & $\begin{array}{c}\text { No. of } \\
\text { observa- } \\
\text { tions. }\end{array}$ & Limits. & Mean. & Calc. & Diff. \\
\hline$\left\{\begin{array}{l}a: c=100: 001 \\
c: a=001: \overline{1} 01 \\
d: a^{\prime}=\overline{1} 01: \overline{1} 00 \\
c: e=001: \overline{7} 04\end{array}\right.$ & $\begin{array}{r}24 \\
16 \\
16 \\
1\end{array}$ & $\begin{array}{c}6739-6756 \\
4753-4827 \\
6350-6419 \\
-\end{array}$ & $\begin{array}{rr}67 & 48 \\
48 & 9 \\
64 & 2 \\
72 & 58\end{array}$ & $\begin{array}{l}- \\
\overline{61} 3 \\
7223\end{array}$ & $\frac{-}{1}$ \\
\hline 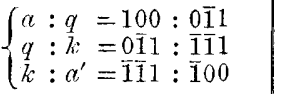 & $\begin{array}{l}13 \\
13 \\
10\end{array}$ & $\begin{array}{llll}63 & 25 & -63 & 52 \\
44 & 55-45 & 21 \\
71 & 1-71 & 20\end{array}$ & $\begin{array}{lr}63 & 37 \\
45 & 7 \\
71 & 12\end{array}$ & $\begin{array}{ll}63 & 43 \\
45 & 8 \\
71 & 9\end{array}$ & $\begin{array}{l}6 \\
1 \\
3\end{array}$ \\
\hline$n^{\prime}: 0=\overline{1} 10: 011$ & 17 & $66 \quad 2-6615$ & 669 & 6612 & 3 \\
\hline$\left\{\begin{array}{l}n: c=1 \overline{1} 0: 001 \\
c: p=001: \overline{1} 11 \\
p: n^{\prime}=\overline{1} 11: \overline{1} 10 \\
c: n^{\prime}=001: \overline{1} 10\end{array}\right.$ & $\begin{array}{r}10 \\
1 \\
1 \\
9\end{array}$ & $\begin{array}{c}8710-8724 \\
\text { - } \\
9238-9253\end{array}$ & $\begin{array}{lr}87 & 16 \\
53 & 30 \\
39 & 7 \\
92 & 44\end{array}$ & $\begin{array}{ll}87 & 19 \\
53 & 21 \\
39 & 20 \\
92 & 41\end{array}$ & $\begin{array}{r}3 \\
9 \\
13 \\
3\end{array}$ \\
\hline$\left\{\begin{array}{l}n: q=1 \overline{1} 0: 0 \overline{1} 1 \\
q: d=0 \overline{1} 1: \overline{1} 01 \\
d: n^{\prime}=\overline{1} 01: \overline{1} 10 \\
q: x=0 \overline{1} 1: \overline{5}: \overline{7} \cdot 12\end{array}\right.$ & $\begin{array}{r}12 \\
10 \\
10 \\
1\end{array}$ & 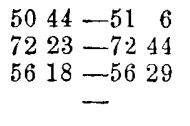 & $\begin{array}{l}5055 \\
7238 \\
5623 \\
2737\end{array}$ & $\begin{array}{ll}50 & 55 \\
72 & 36 \\
56 & 29 \\
27 & 53\end{array}$ & $\begin{array}{r}0 \\
2 \\
6 \\
16\end{array}$ \\
\hline$n: k=1 \overline{1} 0: \overline{1} \overline{1} 1$ & 10 & $8529-8537$ & 8535 & 8531 & 4 \\
\hline$p: k=011: \overline{1} 11$ & 10 & $8757-8810$ & 881 & 8811 & 10 \\
\hline$q: p=0 \overline{1} 1: \overline{1} 11$ & 2 & $9417-9418$ & 9417 & 9428 & 11 \\
\hline
\end{tabular}

Cleavage : perfect parallel to $a-(100)$.

Optics : extinction on $a$ makes an angle of $4^{\circ}$ with the edge $a: m$; on $m$, an angle of $17^{\circ}$ with the same edge; the extinction on $c$ is $30^{\circ}$ with the edge $c a$. An optic axis emerges obliquely through $d$. The birefringence is strong.

Specific gravity: two concordant determinations gave the mean value: Sp. gr. $18^{\circ} / 4^{\circ}=1 \cdot 713$. Mol. vol. $=276.74$.

Topic axes: $\chi=7.4623, \psi=7 \cdot 0108, \omega=6.4169$.

\section{Dibromoinosite Tetra-acetate; Scaly Modification.}

The main difference of this isomeric modification from that just described consists in its crystalline form and in the less degree of solubility in the various solvents. It invariably cryst ullises from its solvents in glistening, thin scales; but under favourable conditions may be obtained from a solution in toluene in more defined crystals.

It melts at $235^{\circ}$ to a clear liquid, which on cooling becomes a foliated, crystalline solid.

100 c.c. of a saturated solution in absolute alcohol at $20^{\circ}$ contain only 0.18 gram, whilst 100 c.c. of boiling absolute alcohol dissolve $3 \cdot 6$ grams. 
Methyl-alcoholic soda, even in the cold, causes a deep orange-brown coloration, and readily decomposes it on boiling. The solution reduces Fehling's solution. On analysis :

0.2314 gave $0.3031 \mathrm{CO}_{2}$ and $0.0781 \mathrm{H}_{2} \mathrm{O} . \quad \mathrm{C}=35.7 ; \mathrm{H}=3.8$.

$0.3371, \quad 0.2355 \mathrm{AgBr} ; \mathrm{Br}=33.6$.

$\mathrm{C}_{6} \mathrm{H}_{6} \mathrm{Br}_{2}\left(\mathrm{O} \cdot \mathrm{CO} \cdot \mathrm{CH}_{3}\right)_{4}$ requires $\mathrm{C}=35.5 ; \mathrm{H}=3 \cdot 8 ; \mathrm{Br}=33 \cdot 7$ per cent.

This modification generally crystallises in very small, slevder scales, quite unsuited for crystallographic investigation, but a measurable crop was finally obtained by slowly cooling a toluene solution.

System : orthorhombic (holo-axial ?).

Ratios of the axes : $a: b: c=2 \cdot 790: 1: 0 \cdot 758$.

Forms : $a=\{100\}, o=\{111\}, m=\{110\}, b=\{0 \overline{1} 0\}$, and $n=\{430\}$.

The habit is shown in Fig. 3 ; the prism zone was characterised

FIG. 3.

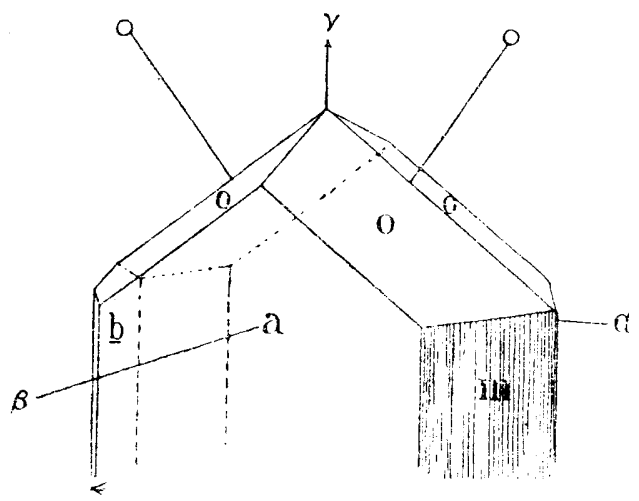

by a series of vicinal and curved faces, especially at the positive end of the axis $b$. The form $b$ always coasisted of a single face (0) $\overline{1} 0)$, and as the crystals were never doubly terminated they may therefore be holo-axial. The form $n$ was only observed once.

\begin{tabular}{|c|c|c|c|c|}
\hline Angle. & $\begin{array}{c}\text { Number } \\
\text { of observa- } \\
\text { tions. }\end{array}$ & Limits. & Mean. & Calculated. \\
\hline $\begin{aligned} a & : m=100: 110 \\
a & : n=100: 430 \\
o & : o=111: 111 \\
o & : o=111: \overline{1} 11 \\
o & : a=111: 100 \\
o & : o=111: 111 \\
o & : m=111: 110\end{aligned}$ & $\begin{array}{l}5 \\
1 \\
6 \\
2 \\
1 \\
2 \\
1\end{array}$ & 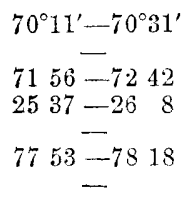 & 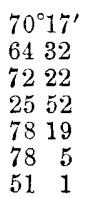 & 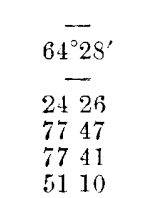 \\
\hline
\end{tabular}


Cleavage : perfect parallel to $a$, fairly good parallel to $m$.

Optics: axial plane parallel to $a$; first positive mean line normal to $c-(001)$; axial angle very wide ; birefringence strong.

Sp. gr. $17^{\circ} / 4^{\circ}=1 \cdot 693$. Mol. vol. $=280^{\circ} 01$.

Topic axes : $\chi=14 \cdot 220, \psi=5 \cdot 097, \omega=3.863$.

$\mathrm{Up}$ to the present, there is no indication of the formation of a higher brominated derivative than the dibromo-tetra-acetate when inosite hexa-acetate is treated with excess of bydrogen bromide at $150^{\circ}$.

\section{Inosite Dibromohydrin.}

In the course of the earlier experiments, when dealing with the viscid part extracted by cold alcohol from the original crude product, it was noticed that on boiling it for some time with water for the purpose of removing the last traces of hydrobromic and acetic acids it gradually dissolved. On evaporating the resulting liquid and allowing it to stand for some time, a crystalline substance separated from the syrupy mother liquor.

The same substance was also obtained when the aqueous washing liquor of the original product referred to above as containing an amorphous substance was repeatedly evaporated in a vacuum and re-dissolved to remove all hydrobromic and acetic acid, and the resulting thick liquid allowed to stand for some time.

The crystalline substance, after being freed as much as possible from the mother liquor by means of a suction filter and pressure between bibulous paper, was crystallised from water, and thus obtained in remarkably fine massive crystals which are quite colourless and of great brilliancy.

This substance is inosite dibromohydrin, and is evidently the product of hydrolysis of a dibromoinosite acetate. It melts at $210^{\circ}$ with partial decomposition, becoming brown and giving off hydrogen bromide. It is readily soluble in water, less so in alcohol or glacial acetic acid, and insoluble in ether, benzene, or acetone.

100 c.c. of a saturated solution in water at $20^{\circ}$ contain 3.15 grams, and 100 c.c. of a boiling aqueous solution contain 60.00 grams; 100 c.c. of a saturated solution in absolute alcohol at $20^{\circ}$ contain 0.55 gram, whilst 100 c.c. of a boiling solution in absolute alcohol contain 6.00 grams.

Silver nitrate added to the aqueous solution gives after a while a slight turbidity, which increases on boiling. Caustic alkalis produce a dark brown coloration on boiling, and Fehling's solution is reduced by it. On analysis :

$\begin{array}{lllll}0.1876 \text { gave } 0.1634 \mathrm{CO}_{2} \text { and } 0.0577 \mathrm{H}_{2} \mathrm{O} . & \mathrm{C}=23 \cdot 7 ; \mathrm{H}=3 \cdot 4 . \\ 0.2095, \quad 0.1801 \mathrm{CO}_{2}, 0.0570 \mathrm{H}_{2} \mathrm{O} . & \mathrm{C}=23 \cdot 4 ; \mathrm{H}=3 \cdot 0 .\end{array}$ 
MÜLLER : INOSITOL (INOSITE).

0.1557 gave $0.1353 \mathrm{CO}_{2}$ and $0.0479 \mathrm{H}_{2} \mathrm{O} . \quad \mathrm{C}=23.7 ; \mathrm{H}=3.4$. $0.5275,0.6471 \mathrm{AgBr} . \quad \mathrm{Br}=52.2$.

$0.3152,0.3880 \mathrm{AgBr} . \quad \mathrm{Br}=52.4$.

$\mathrm{C}_{6} \mathrm{H}_{10} \mathrm{O}_{4} \mathrm{Br}_{2}$ requires $\mathrm{C}=23.5 ; \mathrm{H}=3.3 ; \mathrm{Br}=52.2$ per cent.

System : orthorhombic.

Ratios of the axes : $a: b: c=0 \cdot 7726: 1: 0 \cdot 7654$.

Forms : $m=\{110\}, c=\{001\}, r=\{121\}, b=\{010\}$, and $a=\{100\}$.

The habit was generally tabular, parallel to the basal plane; a few

Fig. 4.

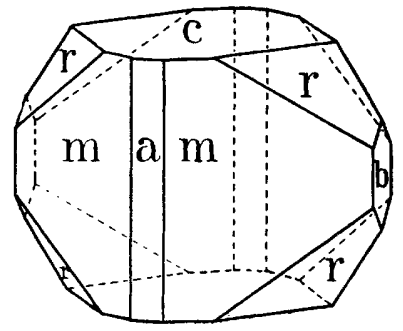

crystals, however, were considerably elongated along the vertical axis. A typical crystal is shown in Fig. 4.

\begin{tabular}{|c|c|c|c|c|c|}
\hline Angle. & $\begin{array}{l}\text { No. of } \\
\text { observa- } \\
\text { tions. }\end{array}$ & Limits. & Mean. & Calc. & Diff. \\
\hline$\left\{\begin{array}{l}m: a=110: 100 \\
m: b=110: 010\end{array}\right.$ & $\begin{array}{l}22 \\
24\end{array}$ & $\begin{array}{l}37^{\circ} 21^{\prime}-38^{\circ} 0^{\prime} \\
527-53\end{array}$ & $\begin{array}{l}37^{2} 37^{\prime} \\
5222\end{array}$ & $\begin{array}{l}37^{\circ} 41^{\prime} \\
5218\end{array}$ & $\begin{array}{l}4^{\prime} \\
4\end{array}$ \\
\hline$\left\{\begin{array}{l}r: c=121: 001 \\
r: r=121: \overline{1} \overline{2} 1\end{array}\right.$ & $\begin{array}{l}10 \\
11\end{array}$ & $\begin{array}{r}6111-6121 \\
12210-12253\end{array}$ & $\begin{array}{r}6115 \\
12232\end{array}$ & $\begin{array}{r}6116 \\
12231\end{array}$ & $\begin{array}{l}1 \\
1\end{array}$ \\
\hline$\left\{\begin{array}{l}r: a=121: 100 \\
r: v=121: 121\end{array}\right.$ & $\begin{array}{l}28 \\
13\end{array}$ & $\begin{array}{l}618-6158 \\
5630-577\end{array}$ & $\begin{array}{ll}61 & 32 \\
56 & 52\end{array}$ & $\begin{array}{ll}6133 \\
5654\end{array}$ & $\begin{array}{l}1 \\
2\end{array}$ \\
\hline$\left\{\begin{array}{l}r: b=121: 010 \\
r: r=121: \overline{121}\end{array}\right.$ & $\begin{array}{r}17 \\
5\end{array}$ & $\begin{array}{l}4221-4252 \\
8456-8531\end{array}$ & $\begin{array}{l}4237 \\
8515\end{array}$ & $\begin{array}{l}4236 \\
85 \quad 12\end{array}$ & $\begin{array}{l}1 \\
3\end{array}$ \\
\hline$m: r=110: 121$ & 8 & $3340-3442$ & 347 & 3412 & 5 \\
\hline$[c r]:\left[c r^{\prime}\right]$ & 5 & $6537-6611$ & 6550 & 6549 & 1 \\
\hline
\end{tabular}

The fundamental angles used were $: r: a: 61^{\circ} 33^{\prime}, r: c=61^{\circ} 16^{\prime}$, these being the means of all the angles in the two zones. The prism faces rarely fall in the zone $a b$, and seem to be always vicinal; a good agreement between the observed and calculated angles is not obtained when the prism angles are used as fundamental angles. 
No good cleavage was observed.

Optical properties: the crystals are biaxial, which proves that this substance, although pseudo-tetragonal, is really orthorhombic; the first mean line is normal to the pinacoid, $a-(100)$, and is positive. Plane of the optic axes $b-(010)$; biref ringence, strong; dispersion, $\rho<v$.

Two plates were ground, perpendicular to the acute and obtuse bi-ectrices respectively, and the axial angle was calculated from observations of $2 \mathrm{Ha}$ and $2 \mathrm{Ho}$ in cedar oil, sodium light being used: $2 \mathrm{E}=67^{\circ} 30^{\prime}$.

Specific gravity, two determinations were made: mean, D22\% $/ 4^{\circ}=$ 2.337. Mol. vol. $=130 \cdot 94$.

Topic axes : $\chi=4.6741, \psi=6.0495, \omega=4 \cdot 6307$.

It was found that the brominated inosite hexa-acetate is hydrolysed by boiling with hydrochloric or hydrobromic acid, and it therefore seems probable that during the action of hydrobromic acid on the hexa-acetate come of the brominated hexa-acetate formed is partly hydrolysed, and that, in fact, the viscid part (insoluble in water) of the product is a derivative intermed ate between the dibromo-hexaacetate and inosite dibromohydrin.

As, however, this viscid compound could not be obtained in a condition fit for analysis, this must for the present remain a surmise.

This also applies to the substance contained in the final aqueous mother liquor, which is obtained in the form of a colourless or slightly yellow substance, resembling gum arabic and containing bromine but in what relation it stands to the crystallised bromohydrin has still to be ascertained.

\section{Products of Debromination by Means of Zinc Dust.}

Having now obtained some of the bromo-derivatives in a definite form, their further examination could be proceeded with, and the study of their behaviour towards reduring agents naturally suggested itself. As a somewhat larger quantity of the dibromo-tetra-acetate, crystallising in massive crystuls, was at disposal, this was taken in hand first.

In a small retort, connected with a condenser, 5 grams of the crystals were dissolved in 30 c.c. glacial acetic acid and to the cold solution 5 grams of zinc dust were gradually added. No hydrogen was given off, but a reaction was indic ited by the agglomeration of the zinc dust particles, and the presence of bromine in the solution could soon be detested by silver ritrate. The reaction was finally assisted by the application of a minute gas flame, and the operation discontinued as soon as the addition of water to some of 
the liquid taken from the retort no longer caused a precipitate of the original substance. The contents of the retort were then mixed with much water, and the residue (mainly cadmium) of the zinc dust filtered off.

The filtrate was then precipitated with a hot solution of silver acetate, and the filtrate from the silver bromide treated with hydrogen sulphide to remove the zinc. On finally evaporating the liquid, there was nothing left except a trace of zinc bromide. The whole of the 5 grams of the substance acted on had thus disappeared.

During the evaporation of the liquid, there was besides that of acetic acid a distinct phenolic odour perceptible, and consequently on repeating the experiment with a fresh quantity of the substance the contents of the retort, after the treatment with zinc dust, were simply mixed with water and distilled. From the milky distillate whic passed over, a heavy oil separated which had the general properties of phenol, and tribromophenol and phenyl benzoate were obtained from it; it failed, however, to give satisfactory colour tests with ferric chloride and bleaching powder solution. Subsequently it became evident that this was caused by the presence of acetic acid. In this second experiment, the aqueous liquid remaining after distillation was again treated with silver acetate to remove the bromine, then with hydrogen sulphide to remove the zinc, and finally evaporated, when nothing was left.

On submitting the scaly form of the dibromo tetra-acetate to the same treatment, the experiment was carried out at a somewhat higher temperature on account of the more sparing solubility of this substance, but the result was precisely the same as in the former case.

Phenol seems then to be the only product of this reaction, and no other substance could be detected which might indicate the intermediate stages of the process which obviously must intervene.

This reaction presents some features of considerable interest. As already mentioned, the dibromo-tetra-acetates on prolonged boiling with acids, such as hydrochloric or hydrobromic, are hydrolysed, but it was found that with glacial acetic acid no perceptible change is produced. The addition of zinc dust to the latter, however, even at a low temperature, not only induces the hydrolysis, but, in the act of eliminating the bromine, breaks down the inosite molecule to phenol.

It became now a matter of special interest to study the behaviour of the monobromo-penta-acetate under the same treatment, and for this purpose 5 grams of the substance with 30 c.c. of glacial acetic acid were introduced into a retort and 5 grams of zinc dust stirred into the mixture; but as the substance is only slighlly soluble, the 
retort was gently warmed. Very little hydrogen was given off, and the substance gradually dissolved. After the lapse of six hours, the retort was allowed to cool, when it-was noticed that the contents remained liquid, an indication that a reaction had taken place.

The addition of water now caused the separation of a colourless, crystalline substance which, on warming, melted and formed a heavy oil, which again became crystalline on cooling. After recrystallising it from dilute alcohol, it separated in soft, slender, prismatic crystals melting at $95^{\circ}$. This substance is readily soluble in alcohol, but less so in water. It was dried in an evacuated desiccator over sulphuric acid :

0.1214 gave $0.2380 \mathrm{CO}_{2}$ and $0.0663 \mathrm{H}_{2} \mathrm{O} . \quad \mathrm{C}=53.4 ; \mathrm{H}=6.0$.

Average of three analyses : $\mathrm{C}=53 \cdot 3 ; \mathrm{H}=5 \cdot 9$.

$$
\mathrm{C}_{14} \mathrm{H}_{18} \mathrm{O}_{8} \text { requires } \mathrm{C}=53 \cdot 5 ; \mathrm{H}=5 \cdot 7 \text { per cent. }
$$

Accordingly, we must assume that in this case the original substance, $\mathrm{C}_{16} \mathrm{H}_{21} \mathrm{O}_{10} \mathrm{Br}$, is reduced to $\mathrm{C}_{16} \mathrm{H}_{22} \mathrm{O}_{10}$, and this then loses acetic acid.

To test this view, an exact determination of the acetyl groups is required, which, however, had to be postponed on account of want of material.

In the mother liquor of this substance, another compound was found, which separates from the aqueous solution on concentration as a colourless, heavy oil remaining liquid at the ordinary temperature for some time and then becoming a crystalline solid. This substance also awaits further examination.

\section{Inosite and Hydrogen Peroxide.}

The description given under the heading, "Action of Hydrogen Peroxide on Cocosite," in the preceding paper (p. 1779), applies in every detail to what takes place when inosite is submitted to the same treatment. The transient, deep purple-blue coloration makes its appearance in the same manner, and finally a stage is reached when further addition of hydrogen peroxide no longer produces this effect. No carbon dioxide is evolved if the addition of the dilute hydrogen peroxide is made in small quantities, and time allowed for the disappearance of the colour in the intervals. Some oxalic acid is formed, which was removed by adding a solution of calcium acetate, and after filtration the liquid was concentrated in a vacuum. By this time, it had become coloured, and in the course of a few days, after exposure to the air, had turned quite dark. On evaporating it further on the water-bath and allowing it to stand in a desiccator, it became dry, but no signs of crystallisation appeared. Its solution readily reduced Fehling's solution, and the characteristic barium rhodizonate was, 
obtained from it; but up to the present I have not been able actually to identify the substance or substances contained in this oxidation product of inosite.

In conjunction with these experiments, trials with other oxidising agents, such as aqueous bromine in presence of iron and platinum black, are being made, which promise to yield results.

Also the action of an ammoniacal solution of silver carbonate has been investigated. A solution of 5 grams of inosite in dilute ammonia was heated to boiling in a retort, and moist silver carbonate added to it at intervals. The silver was thus freely reduced and crystals of ammonium carbonate appeared in the neck of the retort. When no further reduction of silver took place, the operation was discontinued, the liquid filtered off and evaporated. The silver residue, on the other hand, was extracted with dilute hydrochloric acid, and after filtration the acid liquid evaporated on a water-bath. The former yielded a small quantity of ammonium oxalate, whilst from the latter nothing but oxalic acid was obtained. As this result seemed to indicate that the reaction had been carried too far, the experiment was repeated with a less amount of silver carbonate. But in this case also, although some unchanged inosite was recovered, no other substance besides oxalic acid could be found.

In conclusion, I beg to offer my thanks to the managers of the Davy-Faraday Laboratory for having afforded me the opportunity of carrying out these investigations.

Davy-Faraday Laboratory, ROYAL INSTITUTION. 